\title{
Using Routine Ambulance Inspection Report Application to Reduce Wasted Time in Emergency Medical Services
}

Korakot Apiratwarakul ${ }^{1}$, Kamonwon lenghong ${ }^{1 *}$, Takaaki Suzuki ${ }^{2}$, Ismet Celebi $^{3}$, Vajarabhongsa Bhudhisawasdi ${ }^{1}$, Somsak Tiamkao ${ }^{4}$

${ }^{1}$ Department of Emergency Medicine, Faculty of Medicine, Khon Kaen University, Khon Kaen, Thailand; ${ }^{2}$ Department of Emergency and Critical Care Medicine, University of Tsukuba Hospital, Tsukuba, Japan; ${ }^{3}$ Department of Paramedic, Gazi University, Ankara, Turkey; ${ }^{4}$ Department of Medicine, Faculty of Medicine, Khon Kaen University, Khon Kaen, Thailand

Edited by: Sasho Stolesk Citation: Apiratwarakul K, lenghong K, Suzuki T, Celebi I Bhudhisawasdi V, Tiamkao S. Using Routine Ambulance Emergency Medical Services. Open Access Maced J Med Sci. 2021 Apr 20; 9E:298-301 https://doi.org/10.3889/oamjms.2021.6022 rds: Ambulances; Emergency mobile units; Emergency medical services; Report; Time
Correspondence: Kamonwon lenghong, Departmen of Emergency Medicine, Faculty of Medicine, Khon Kaen University, Khon Kaen, Thailand.
E-mail: kamonwan@kku.ac.th Received: 19-Mar-2021 Revised: 10-Apr-2021 Accepted: 12-Apr-202 Copyright: ๑ 2021 Korakot Apiratwarakul, monwon lenghong, Takaaki Suzuki, Ismet Celebi, Vajarabhongsa Bhudhisawasdi, Somsak Tiamkao
Funding: This research did not receive any financial support competing interests exist.
com have declared that competing interests exist.
naccess article distributed Open Access: This is an open-access article distributed
under the terms of the Creative Commons Attributionunder the terms of the Creative Commons Attribution-
Commercial 4.0 International License (CC BY-NC 4.0)

\begin{abstract}
BACKGROUND: Ambulance inspections make up part of the emergency medical services (EMS) to keep operations running smoothly as well as to maximize and maintain the safety of vehicles used for delivery of both staff and patients. The EMS of Srinagarind Hospital has been using an ambulance inspection report application since January 2020. Nevertheless, there has been no comparative study of the benefits associated with the use of this specification.

AIM: The aim of this study was to compare the advantages of an ambulance inspection report application and paper checklist.

METHODS: This cross-sectional study was conducted amid the EMS at a university hospital in Thailand. Data gathering was carried out by employing the Srinagarind Hospital database and ambulance inspection report application throughout January 1, 2019, and December 31, 2020.

RESULTS: A total of 2350 ambulance inspections were recorded during the 2-year study period. Recognition times for ambulance inspections incorporating paper checklist and inspection with application were $35.5 \pm 9.4$ min and 1.02 $\pm 0.5 \mathrm{~min}$, respectively $(P<0.001)$. Action times were $25.2 \pm 5.1 \mathrm{~min}$ and $1.04 \pm 0.2 \mathrm{~min}$, respectively. Ambulance inspection compliance rate with the application was $95.3 \%$ and $70.1 \%$ with a paper checklist.

CONCLUSION: Ambulance inspections carried out with an application can reduce recognition and action time, and increase ambulance inspection compliance rate.
\end{abstract}

\section{Introduction}

Routine ambulance inspections are part of emergency medical services (EMS) to keep operations running smoothly to ensure the safety of vehicles employed for delivery of both staff and patients. Usually, as standard, there should be checks during each shift 2-3 times a day, including when the ambulance is used in other missions, such as in the issuance of sports competitions.

The previous studies have shown that ambulance inspections ought to be given priority with time taken to closely examine medical supplies and resuscitation equipment in the ambulance to maximize performance [1]. This duty incorporated ambulance drivers or EMS crew members in conjunction with the head nurse of the shift. There is a paper checklist of items to be checked according to the standards of the Thai National Institute of Emergency Medicine [1], [2].

A problem was discovered according to a lack of regular checks or when abnormalities were detected.
Inspection results reported to the head responsible were delayed - especially during the afternoon or night shifts. A study of EMS safety incidences revealed that ambulance-related issues were the second highest reported with $16 \%$ of incidence. Therefore, it is recommended that ambulance safety checks take place regularly [2], [3], [4]. This information is aimed at both hospital personnel and the individual concerning ambulance safety to reduce both loss of life and morbidity [5], [6], [7]. It was also found that when ambulance inspections took place in full, such actions by the operator made the patient feel safer [8], [9], [10]. The use of incident reporting applications instead of paper reports plays an important role in both real-time reporting and the ability to assess the consistency of reporting. Hence, modified work processes reduce time wastage [11], [12], [13].

The EMS at Srinagarind Hospital have been using an ambulance inspection report application since January 2020. However, there has not been any comparative study of the benefits of the use of such an application. 


\section{Methods}

\section{Study design and setting}

This cross-sectional study was conducted amid the EMS of Srinagarind Hospital, a tertiary care and university hospital with approximately 2500 annual operations in Khon Kaen, Thailand. EMS personnel consist of doctors, nurses, advanced emergency medical technicians (AEMTs), emergency medical technicians (EMTs), and the ambulance driver on duty. Data were obtained from the application for ambulance inspection and database of the EMS at Srinagarind Hospital throughout the years 2019-2020. Ethical approval was provided by the Khon Kaen University Ethics Committee for Human Research (HE641153). The requirement for informed consent was waived since confidentiality protection had already been guaranteed. Accordingly, participants were not identified by name, but instead by a unique study number.

\section{Participants}

We included all routine ambulance inspections between January 1, 2019, and December 31, 2020, with (1) in 2019, data gathering from an ambulance inspection paper checklist and (2), in 2020, data gathering from the ambulance inspection report application. Cases with missing data were excluded from the study.

\section{Data collection}

We utilized the EMS database and ambulance inspection report application to collect demographic data including age, sex, time of ambulance checking, recognition time, and action time. The ambulance inspection report is carried out through Google Forms which then generates a QR code attached to the front windshield of the ambulance for the EMS crews to scan before operations. The 20 protocol checklist items are as follows: (1) Battery, (2) fuel, (3) starter, (4) leakage, (5) radiator, (6) breaks, (7) wheels, (8) gears, (9) electricity, (10) lights, (11) steering wheel, (12) oxygen tank, (13) fire extinguishers, (14) air conditioning, (15) siren, (16) radio equipment, (17) ventilation system, (18) resuscitation box, (19) personnel protective equipment, and (20) traffic cones. After completion and sending information through the application, an e-mail will alert the chief nurse who has the duty to check and control ambulance operations.

\section{Definitions}

Recognition time is defined as the period of time from the complete submission of the ambulance inspection to when the nurse in-charge of the inspection is informed. Action time is defined as the period from accepting the ambulance inspection results to the order to fix the issue.

\section{Sample size and statistical analysis}

Sample size was calculated based on the number of ambulance inspections in 2018 [14]. To achieve a significance level of $5 \%$ and power of test of 0.75 , we determined that a sample size of 2350 would be required. Statistical analysis was performed using IBM SPSS for Windows version 26.0, Khon Kaen University license (SPSS Inc., Chicago, IL, USA). Categorical data were presented as percentages with continuous data presented employing mean and standard deviation. Univariable analysis was carried out using a two sample t-test for numerical data and Pearson's correlation for data relationship between groups.

\section{Results}

A total of 2350 ambulance inspections were recorded during a 2-year study period. Subjects' characteristics are shown in Table 1. EMS crew mean age amid ambulance inspection with the application was $31.8 \pm 5.4$ years, with $94.5 \%(n=1110)$ being male. The most common EMS role of those completing ambulance inspections with the paper checklist and application were EMTs ( $87.6 \%$ and $88.6 \%$, respectively). Operations were most commonly performed during the morning shift (8.00 am-4.00 pm) in both groups.

Table 1: Characteristics of the subjects

\begin{tabular}{|c|c|c|c|}
\hline Characteristics & $\begin{array}{l}\text { Ambulance } \\
\text { inspection with } \\
\text { paper checklist } \\
(\mathrm{n}=1175), \mathrm{n}(\%)\end{array}$ & $\begin{array}{l}\text { Ambulance } \\
\text { inspection with } \\
\text { application } \\
(\mathrm{n}=1175), \mathrm{n}(\%)\end{array}$ & $p$-value \\
\hline Age (years), mean \pm SD & $32.4 \pm 5.6$ & $31.8 \pm 5.4$ & 0.742 \\
\hline \multicolumn{4}{|l|}{ Gender } \\
\hline Male & $1085(92.3)$ & $1110(94.5)$ & 0.652 \\
\hline \multicolumn{4}{|l|}{ EMS role } \\
\hline Nurse & $51(4.3)$ & $45(3.8)$ & 0.522 \\
\hline AEMTs & $95(8.1)$ & $89(7.6)$ & 0.620 \\
\hline EMTs & $1029(87.6)$ & $1041(88.6)$ & 0.740 \\
\hline \multicolumn{4}{|l|}{ Operation duration } \\
\hline Morning shift & $410(34.9)$ & $405(34.5)$ & 0.654 \\
\hline Afternoon shift & $385(32.8)$ & $388(33.0)$ & 0.620 \\
\hline Night shift & $380(32.3)$ & $382(32.5)$ & 0.410 \\
\hline Recognition time (min), mean \pm SD & $35.5 \pm 9.4$ & $1.02 \pm 0.5$ & $<0.001^{*}$ \\
\hline Action time $(\mathrm{min})$, mean $\pm \mathrm{SD}$ & $25.2 \pm 5.1$ & $1.04 \pm 0.2$ & $<0.001^{*}$ \\
\hline
\end{tabular}

Recognition times for ambulance inspection with paper checklist and inspection with application were $35.5 \pm 9.4 \mathrm{~min}$ and $1.02 \pm 0.5 \mathrm{~min}$, respectively $(p<0.001)$. Action times were $25.2 \pm 5.1 \mathrm{~min}$ and 1.04 $\pm 0.2 \mathrm{~min}$, respectively.

Observation of ambulance inspections with paper checklist revealed a total of 1175 indications with 824 compliances $(70.1 \%)$, as shown in Table 2 . We also found an ambulance inspection compliance rate with the application of $95.3 \%$ (1120/1175). In the application group, 
according to all 20 ambulance inspection checklist items, subjects demonstrated a significantly higher compliance rate than the paper checklist group $(p<0.001)$.

Table 2: Checklist items of ambulance inspection

\begin{tabular}{llll}
\hline Checklist items & $\begin{array}{l}\text { Ambulance } \\
\text { inspection with } \\
\text { paper checklist } \\
(\mathrm{n}=1175), \mathrm{n}(\%)\end{array}$ & $\begin{array}{l}\text { Ambulance } \\
\text { inspection with } \\
\text { application } \\
(\mathrm{n}=1175), \mathrm{n}(\%)\end{array}$ & \\
\hline Overall check & $824(70.1)$ & $1120(95.3)$ & $<0.001^{*}$ \\
Battery & $824(70.1)$ & $1119(95.2)$ & $<0.001^{*}$ \\
Fuel & $820(69.8)$ & $1118(95.1)$ & $<0.001^{*}$ \\
Starter & $815(69.4)$ & $1118(95.1)$ & $<0.001^{*}$ \\
Leakage & $822(70.0)$ & $1118(95.1)$ & $<0.001^{*}$ \\
Radiator & $821(69.9)$ & $1119(95.2)$ & $<0.001^{*}$ \\
Breaks & $823(70.0)$ & $1120(95.3)$ & $<0.001^{*}$ \\
Wheels & $820(69.8)$ & $1119(95.2)$ & $<0.001^{*}$ \\
Gears & $822(70.0)$ & $1120(95.3)$ & $<0.001^{*}$ \\
Electricity & $821(69.9)$ & $1120(95.3)$ & $<0.001^{*}$ \\
Lights & $820(69.8)$ & $1118(95.1)$ & $<0.001^{*}$ \\
Steering wheel & $821(69.9)$ & $1119(95.2)$ & $<0.001^{*}$ \\
Oxygen tank & $820(69.8)$ & $1120(95.3)$ & $<0.001^{*}$ \\
Fire extinguishers & $820(69.8)$ & $1119(95.2)$ & $<0.001^{*}$ \\
Air conditioning & $815(69.4)$ & $1120(95.3)$ & $<0.001^{*}$ \\
Siren & $819(69.7)$ & $1120(95.3)$ & $<0.001^{*}$ \\
Radio equipment & $821(69.9)$ & $1119(95.2)$ & $<0.001^{*}$ \\
Ventilation system & $821(69.9)$ & $1120(95.3)$ & $<0.001^{*}$ \\
Resuscitation box & $822(70.0)$ & $1119(95.2)$ & $<0.001^{*}$ \\
Personnel protective equipment & $821(69.9)$ & $1118(95.1)$ & $<0.001^{*}$ \\
Traffic cones & $823(70.0)$ & $1120(95.3)$ & $<0.001^{*}$ \\
\hline
\end{tabular}

\section{Discussion}

The present study involved the use of an application to monitor ambulance inspection instead of paper to reduce wasted time amid EMS. The primary persons responsible for ambulance inspection were the EMTs, that is, ambulance drivers and the on-duty nurse who acted as the repeat inspector and supervisor. Traditional workflow starts from the EMS crews' paperbased reports sent to the responsible chief nurse who waits until the supervisor decides to order a solution and then communicates said solution to the operator. Unfortunately, this system of work includes delays [1], [2].

In addition, ambulance safety is critical because delaying ambulance inspection can pose a safety potential risk to both staff and patients using the service. Thus, by converting the process to this application, the supervisors have access to real-time reporting, resulting in immediate decision-making [5], [8], [10]. According to the study results, recognition time and action time in the application groups (wasted time) were reduced to almost $1 \mathrm{~h}$ per ambulance inspection. Hence, the utilization of the application improves the consistency of inspections. This may be due to the use of the reporting application, whereby the head of the unit will immediately know the results of the performance, which is different to the paper report which can be written at any other subsequent time [12].

We are aware that our study had some potential limitations. First, data were collected from just a single EMS center in a tertiary care hospital. Moreover, the study design was retrospective which may have resulted in incomplete data [14], [15], [16], [17].

\section{Conclusion}

Ambulance inspections with an application can reduce recognition and action time, and increase ambulance inspection compliance rate.

\section{Acknowledgments}

The authors wish to thank Mr. Ross Lacey for acting as an English consultant.

\section{References}

1. Harkins S. Vehicle maintenance and inspections. Emerg Med Serv. 2001;30(11):65-7.

PMid:11715793

2. Kupas DF, Shayhorn MA, Green P, Payton TF. Structured inspection of medications carried and stored by emergency medical services agencies identifies practices that may lead to medication errors. Prehosp Emerg Care. 2012;16(1):67-75. https://doi.org/10.3109/10903127.2011.621046 PMid:22035224

3. Gallagher JM, Kupas DF. Experience with an anonymous webbased state EMS safety incident reporting system. Prehosp Emerg Care. 2012;16(1):36-42. https://doi.org/10.3109/109031 27.2011.626105

PMid:22128906

4. Brice JH, Studnek JR, Bigham BL, Martin-Gill C, Custalow CB, Hawkins $\mathrm{E}$, et al. EMS provider and patient safety during response and transport: Proceedings of an ambulance safety conference. Prehosp Emerg Care. 2012;16(1):3-19. https://doi. org/10.3109/10903127.2011.626106

PMid:22023217

5. Slattery DE, Silver A. The hazards of providing care in emergency vehicles: An opportunity for reform. Prehosp Emerg Care. 2009;13(3):388-97. https://doi. org/10.1080/10903120802706104

PMid:19499479

6. Blau G, Chapman S, Boyer E, Flanagan R, Lam T, Monos C. Correlates of safety outcomes during patient ambulance transport: A partial test of the Haddon matrix. J Allied Health. 2012;41(3):e69-72.

PMid:22968779

7. Apiratwarakul K, lenghong K, Bhudhisawasdi V, Gaysonsiri D, Tiamkao S. Response Times of Motorcycle Ambulances during the COVID-19 Pandemic. Open Access Maced J Med Sci. 2020;8(T1):526-9. https://doi.org/10.3889/oamjms.2020.5527

8. Venesoja A, Castrén M, Tella S, Lindström V. Patients' perceptions of safety in emergency medical services: An interview study. BMJ Open. 2020;10(10):e037488. https://doi. org/10.1136/bmjopen-2020-037488

PMid:33087370

9. Taymour RK, Abir M, Chamberlin M, Dunne RB, Lowell M, Wahl $\mathrm{K}$, et al. Policy, practice, and research agenda for emergency medical services oversight: A systematic review and 
environmental scan. Prehosp Disaster Med. 2018;33(1):89-97. https://doi.org/10.1017/s1049023x17007129

PMid:29293077

10. Bashiri A, Savareh BA, Ghazisaeedi M. Promotion of prehospital emergency care through clinical decision support systems: Opportunities and challenges. Clin Exp Emerg Med. 2019;6(4):288-96. https://doi.org/10.15441/ceem.18.032 PMid:31910499

11. Li CZ, Zhao Y, Xiao B, Yu B, Tam VW, Chen Z, et al. Research trend of the application of information technologies in construction and demolition waste management. J Clean Prod. 2020;263:121458. https://doi.org/10.1016/j.jclepro.2020.121458

12. Mohammed M, Shafiq N, Abdallah NA, Ayoub M, Haruna A. A review on achieving sustainable construction waste management through application of 3R (reduction, reuse, recycling): A lifecycle approach. IOP Conf Ser Earth Environ Sci. 2020;476:012010. https://doi.org/10.1088/1755-1315/476/1/012010

13. He $\mathrm{M}$, Jin $\mathrm{Y}$, Zeng $\mathrm{H}$, Cao J. Pricing decisions about waste recycling from the perspective of industrial symbiosis in an industrial park: A game model and its application. J Clean Prod 2020;251:119417. https://doi.org/10.1016/j.jclepro.2019.119417

14. Apiratwarakul K, Kongudom N, Kotruchin P, Phungoen $P$, Larthum K. Visits to the emergency department during the 2020 COVID-19 outbreak in Thailand. J Med Assoc Thai. 2021;104 Suppl 1:S1-4. https://doi.org/10.35755/jmedassocthai.2021. s01.12122

15. Apiratwarakul K, lenghong K, Gaysonsiri D, Mitsungnern T, Buranasakda M, Bhudhisawasdi V. The effectiveness of oxygen-powered inhalation devices in prehospital care. J Med Assoc Thai. 2020;103 Suppl 6:58-60.

16. lenghong $\mathrm{K}$, Kleebbuakwan $\mathrm{K}$, Apiratwarakul $\mathrm{K}$, Phungoen $\mathrm{P}$, Gaysonsiri D, Bhudhisawasdi V. Comparison of cleaning methods for ultrasound probes at an emergency department in a resource-limited country. J Med Assoc Thai. 2020;103 Suppl 6:67-71.

17. Apiratwarakul $K$, Songserm $W$, lenghong $K$, Phungoen $P$, Gaysonsiri D, Bhudhisawasdi V. The role of mechanical cardiopulmonary resuscitation devices in emergency medical services. J Med Assoc Thai. 2020;103 Suppl 6:98-101. 